\title{
Dalga etkisi sonucu farklı yerleşim şekillerine sahip kazık grupları etrafında oluşan yerel ve genel oyulmaların deneysel araştırılması
}

\section{Experimental Investigation of Local and Global Scour Formed around Pile Groups with different settlements as a Result of the Wave Effect}

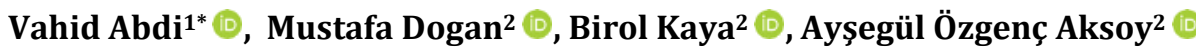 \\ ${ }^{1}$ Dokuz Eylül Üniversitesi Fen Bilimleri Enstitüsü, Hidrolik-Hidroloji ve Su Kaynakları Programı, İzmir, TÜRKIYE \\ 2 Dokuz Eylül Üniversitesi Mühendislik Fakültesi, İnşaat Mühendisliği Bölümü, İzmir, TÜRKIYE \\ Sorumlu Yazar / Corresponding Author*: vahid.aabdi@gmail.com \\ Geliş Tarihi / Received: 13.02.2020 \\ Araştırma Makalesi/Research Article \\ Kabul Tarihi / Accepted: 21.04.2020 \\ DOI:10.21205/deufmd.2020226610 \\ Atıfșekli/How to cite: ABDI, V., DOGAN, M., KAYA, B., OZGENC AKSOY, A.(2020). Dalga etkisi sonucu farkl yerleșim șekillerine sahip kazık \\ grupları etrafinda oluşan yerel ve genel oyulmaların deneysel araștırılması. DEUFMD 22(66), 749-757.
}

\section{Öz}

Gerçekleştirilen çalışmada, kıyı bölgesinde yer alan silindirik kazık grupları etrafında dalga kaynaklı yerel zemin hareketleri deneysel olarak araștırılmıștır. Deneyler 33 m uzunluğa, 3.6 m genișliğe ve $1.2 \mathrm{~m}$ derinliğe sahip bir dalga kanalında gerçekleştirilmiştir. Kanalın açık deniz kesiminde dalıp çıkmalı (plunger type) türde bir dalga üreteci yer almakta olup bu üreteç yardımıyla farklı yükseklik ve periyotlara sahip düzenli dalgalar oluşturulmuştur. Aynı çapa sahip kazıklar farklı şekillerde yerleștirilerek dört farklı kazık grup yapısı olușturulmuștur. Deneyler iki farklı irilikte üniform kum taban malzemesi kullanılarak gerçekleştirilmiştir. Kazıklar ve kazık grupları etrafındaki oyulmalar zamana bağlı olarak ölçülmüştür. Böylece kazık grubu etrafındaki yerel ve genel oyulma derinlikleri belirlenebilmiștir.

Anahtar Kelimeler: Dalga etkisi, zemin hareketleri, farklı yerleşimli kazık grupları, yerel ve genel oyulma.

\section{Abstract}

In this study, local sediment movements caused by waves around cylindrical pile groups in the coastal region were investigated experimentally. The experiments were carried out in a wave channel with a length of $33 \mathrm{~m}$, a width of $3.6 \mathrm{~m}$ and a depth of $1.2 \mathrm{~m}$. Regular waves with different heights and periods have been generated by a wave generator, which is located on the offshore side of the wave channel. Four different pile group structures were generated by placing piles of the same diameter in different ways. The experiments were carried out by using two different uniform sand bed materials. The time dependent scour depths around the piles and pile groups were measured. Accordingly, local and global scouring depths around the pile group could be determined. Keywords: Wave effect, sediment motion, wave groups with different settlements, local and global scour. 


\section{Giriș}

Silindirik kazıklar, uzun süredir kıyı bölgelerinde iskele ve rıhtım yapılarının temellerini oluşturmak amacıyla kullanılmaktadır. Bu yapılar genellikle belirli biçimde dizilmiş grup halinde kıyı bölgesi deniz tabanına oturmaktadır Özelikle yakın kıyı bölgesinde yer alan ve așınabilir bir deniz tabanı üzerinde bulunan silindirik kazıkların etrafında, dalga ve/veya akıntı etkisi sonucu yerel zemin hareketleri meydana gelebilmektedir. Bu kadar fazla kullanılan ve dayanım açısından öneme sahip olan bu kazıkların etrafında oluşacak oyulmalar incelenmeli ve oluşacak sorunlar öngörülerek tasarım aşamasında gerekli önlemler alınmalıdır. Tasarlanacak kazıklar dalgalara ve akıntılara maruz kalmakta ve bunun sonucunda etraflarında oyulmalar oluşabilmektedir. Dalgalar ve akıntılar önlenemeyeceğinden dolayı kazıkların etrafında oluşabilecek oyulmaların önlenmesi dolayısıyla yapının hasardan korunması için çalışmalar yapılması gerekmektedir.

Konu ile ilgili literatürde farklı çalışmalar bulunmaktadır. Bu çalıșmaların önemli bir kısmını kararlı akıntı durumundaki çalışmalar oluşturmaktadır. Dalga etkisinin araştırıldığı çalışmalar sınırlı sayıdadır. Aşağıda, incelenen konu ile ilişkili literatürden seçme çalışmalar özetlenerek verilmiștir.

[1] çalışmasında, dalgalara maruz kalan farklı yerleșimlere sahip kazık grupları etrafında oluşan oyulma üzerine deneysel bir araştırma gerçekleştirilmiştir. Hem oyulma hem de taban kayma gerilmesi ölçümleri yapılmıştır. Yan yana ve arka arkaya ikili grup şeklinde, üçlü ve dörtlü gruplara sahip üçgen ve kare olmak üzere yedi farklı çeşit kazık grubu test edilmiştir. Farklı kazık aralıkları ve Keulegan-Carpenter (KC) sayısı değişimleri araştırılmıştır.

[2] çalışmasında dalga etkisine maruz tekil kazık ve farklı yerleşim şekillerindeki kazık grupları etrafındaki oyulmalar deneysel olarak araștırılmıștır. Tekil kazık durumu ile beraber dört farklı grup yerleşiminin denendiği çalışma sonucunda, KC sayısı büyüdükçe oluşan oyulma çukuru boyutlarının da büyüdüğü belirtilmektedir. Kazık grubu etrafında oluşan oyulmaların, benzer etkiler altındaki tekil kazık etrafinda oluşan oyulmalardan genel olarak büyük olduğu sonucuna varılmıștır.
[3] çalıșması kapsamında dalgalara maruz kalan kazık grubu etrafındaki oyulma derinliğinin tahmini için Veri İşlem Grup Yönteminin (GMDH) yeni bir uygulaması sunulmuştur. GMDH ağı oyulma tahmini için hazırlık aşamasında Levenberg-Marquart yöntemi kullanılarak geliștirilmiștir. Düzenli dalgalarla oluşan oyulma derinliği dört boyutsuz parametrenin fonksiyonu olarak modellenmiștir. Bu dört parametre: Reynolds sayısı (Re), dane Reynolds sayısı $\left(\mathrm{Re}_{\mathrm{d}}\right)$, Keulegan-Carpenter sayısı (KC) ve Shields parametresidir $(\theta)$. GMDH-LM ile elde edilen sonuçlar Uyarlanabilir Neuro-Fuzzy Çıkarım Sistemi ve ampirik denklemlerden elde edilen sonuçlarla karşıllaştırılmıştır. Oyulma tahmininin deneysel çalışmaları temiz su koşullarında gerçekleştirilmiştir. GMDH ağı, RBF-NN ve ANFIS modellerinin en iyi sonuçları istatistiksel yöntemlerle sınanmıştır.

Sunulan çalışmada farklı yerleșimli kazık grupları etrafındaki oyulmalar hem zamana bağlı olarak hem nihai durum için deneysel olarak belirlenmiștir. Böylece kazık yerleşim şekillerinin oyulma sürecine etkisi hem oyulmanın gelișim süreci için hem de denge durumu için değerlendirilebilmiştir.

\section{2. Çalışma Yöntemi}

Kazık grupları için şematik olarak Şekil 1'de gösterilen dört farklı kazık grup yerleşimi ile deneyler yapılmıştır.

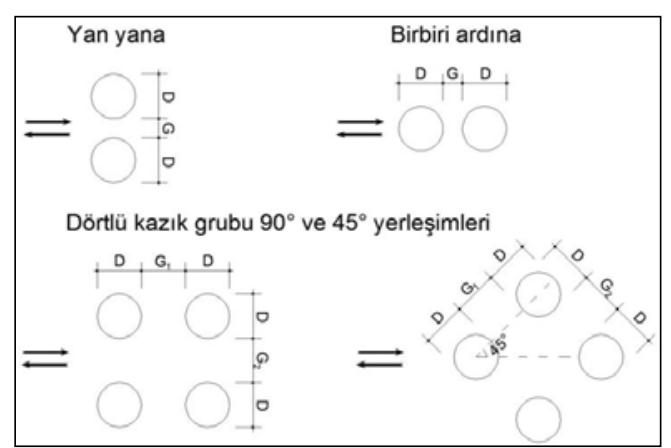

Şekil 1. Deneysel çalışmalardaki farklı kazık grup yerleșim șekilleri.

Çalıșma kapsamında; bir biri ardına yerleştirilen aynı çaplı iki kazık kullanılarak oluşturulan kazık grubu, aynı çaplı iki kazığın 
dalga ilerleme yönüne paralel olarak arka arkaya yerleștirilmesi ile olușturulan kazık grubu, dalga ilerleme yönüne göre $90^{\circ}$ yerleşimli dörtlü kazık grubu ve son olarak dalga ilerleme yönüne göre $45^{\circ}$ yerleşimli dörtlü kazık grubu deneyleri gerçekleştirilerek kazık grubu etrafındaki oyulma yapısı araştırılmıștır.

Her kazığın ön tarafına dalga yönüne paralel olarak UVP cihazına (Șekil 2) ait bir adet algılayıcı yerleştirilmiştir. Deney sonrasında utrasonik yöntem ile çalışan UltraLab UWS-The Lab Echosounder cihazı (Şekil 3) yardımıyla deney sonrasında kanaldaki su boşaltılmadan kazıkların konuşlandırıldığı bölge civarındaki nihai taban batimetrisi çıkarılmıştır.

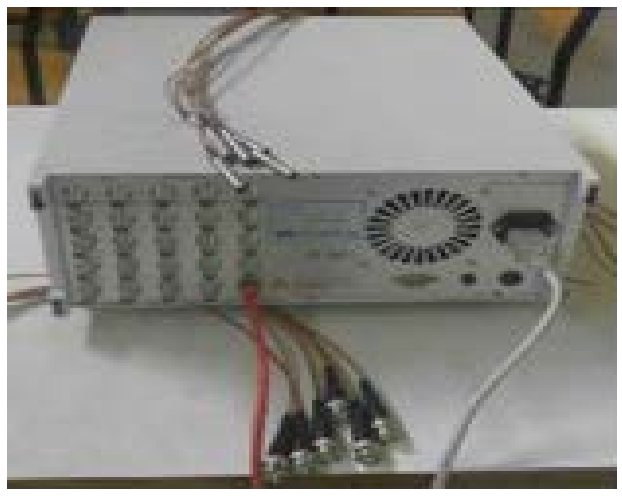

Şekil 2. UVP cihazı ve algılayıcıları.

UVP cihazı yüksek frekanslı ses dalgaları prensibi ile çalışan bir cihaz olup temel olarak su akımı içerisinde hız profili çıkarmak için kullanılmaktadır. Ölçüm yöntemi olarak ses dalgalarının su içindeki parçacıklara çarptıktan sonra yansıyarak geri dönmesi esas olduğundan, cihazın ikincil bir özelliğinden yararlanılarak su ortamı içerisinde yerel zemin hareketlerinin zamana bağlı olarak ölçülmesi gerçekleştirilebilmektedir. Bu ölçüm yöntemi ile ilgili ayrıntılı bilgiler [4] çalışmasında yer almaktadır.

Deneysel çalışmalarda kullanılan dalga kanalı, Dokuz Eylül Üniversitesi İnşaat Mühendisliği Bölümü Hidrolik Laboratuvarı bünyesinde yer almaktadır (Şekil 4).

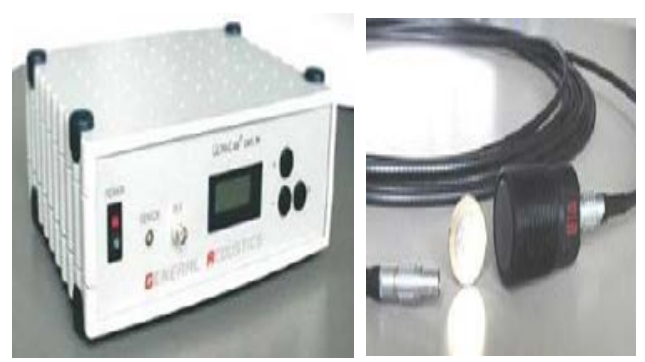

Şekil 3. UltraLab UWS - The Lab Echosounder cihazı ve ölçüm sensoru.

Dalga kanalı, 33 m uzunluğa ve $1.2 \mathrm{~m}$ derinliğe sahip olup, kanal genişliği boyunca akım yapısının ve zemin hareketlerinin değişiminin araștırılmasına olanak sağlayacak șekilde $3.6 \mathrm{~m}$ genişliğe sahiptir. Dalga kanalının açık deniz tarafında bir düzenli dalga üreteci yer almaktadır bu üreteç elektronik hız kontrol cihazı ile kumanda edilmekte olup, üretilecek dalgaların periyotları hassas bir şekilde ayarlanabilmektedir. Şekil 4'te dalga kanalı ve test kazıkları ile ölçüm donanımlarının yerleşimi şematik olarak gösterilmektedir.

Şekil 4'te gösterildiği gibi test kazıklarının bulunduğu bölgede yer alan çukura deneylerde kullanılan iki tipteki üniform kum taban malzemeleri serilmiștir. Dane medyan çapları $\mathrm{d}_{50}=0.55 \mathrm{~mm}$ ve $\mathrm{d}_{50}=1.85 \mathrm{~mm}$ olan bu kumlara ait elek analizi grafiği Şekil 5 'te verilmektedir.

\section{Deneysel Bulgular}

Tablo 1'de olduğu gibi arka arkaya, yan yana ve dörtlü olarak dalga ilerleme yönüne göre hem $90^{\circ}$ hem de $45^{\circ}$ açılar oluşacak şekilde yerleștirilen kazık grubu için yapılan deney listesi verilmektedir. Burada D kazık çapı, H dalga yüksekliği, T dalga periyodu ve L dalga boyunu ifade etmektedir.

Şekil 6'da aynı çaplı iki kazığın yan yana yerleștirilmesi ile oluşan kazık grubu UVP algılayıcıları ile birlikte gösterilmektedir. 


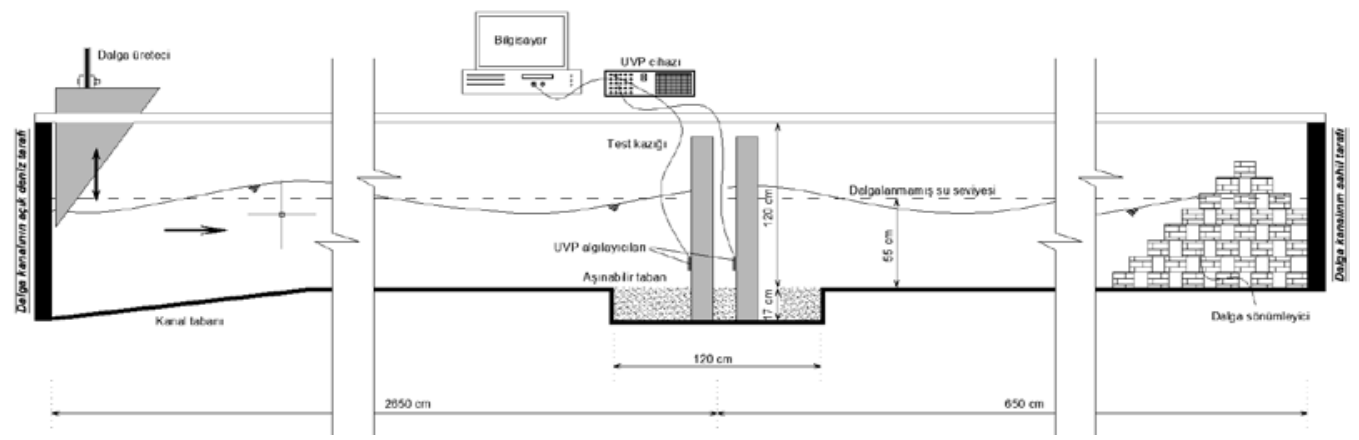

Şekil 4. Deneysel çalışmaların gerçekleştirildiği dalga kanalı ve arka arkaya yerleştirilen kazıkların ve UVP algılayıcılarının şematik gösterimi.

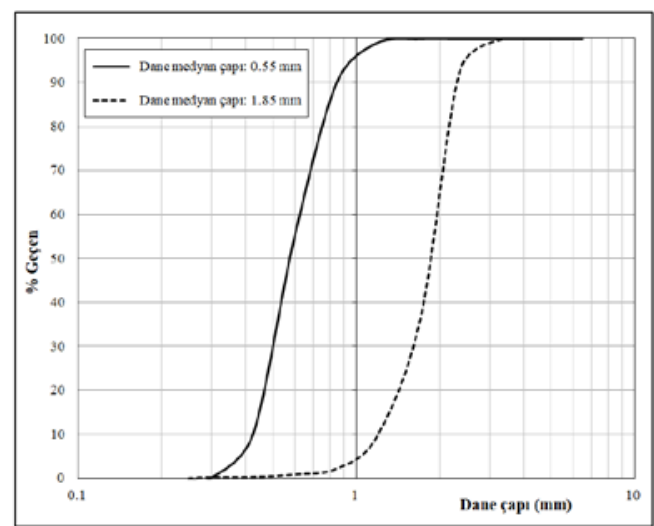

Şekil 5. Laboratuar deneylerinde kullanılan malzeme granülometrisi

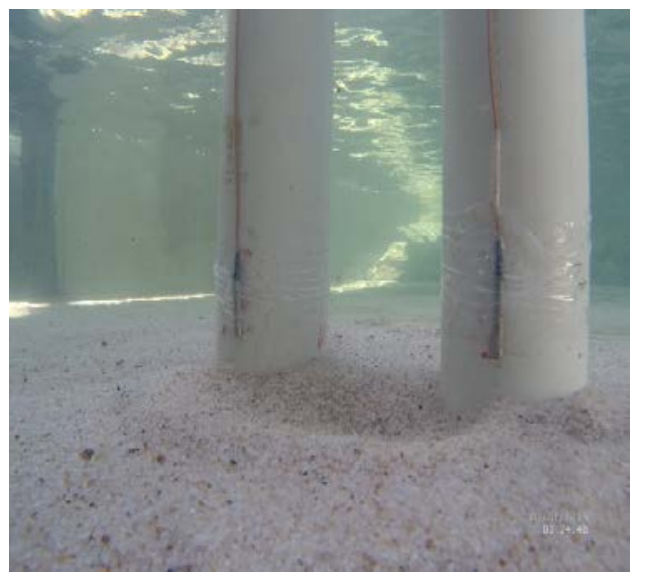

Şekil 6. Deneylerde yan yana kazlk grubu ve oyulma ölçüleri için kullanılan UVP algılayıcıları.

Şekil 7'de aynı çaplı iki kazığın arka arkaya yerleştirilmesi ile oluşan kazık grubu UVP algılayıcıları ile birlikte gösterilmektedir.

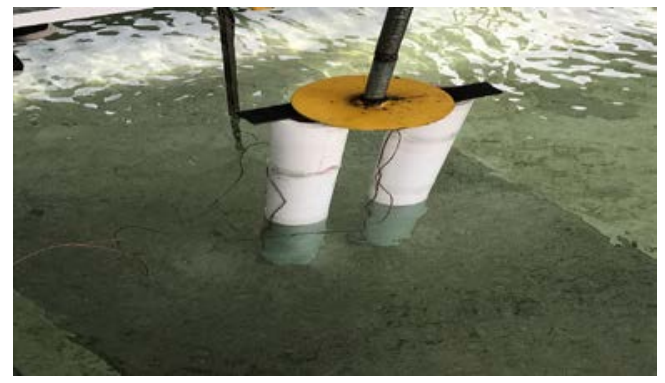

Şekil 7. Deneylerde arka arkaya yerleștirilen kazık grubu ve oyulma ölçüleri için kullanılan UVP algılayıcıları.

Şekil 8'de aynı çaplı dört kazığın dalga ilerleme yönüne göre $45^{\circ}$ açı ile yerleştirilmesi ile oluşan kazık grubu UVP algılayıcıları ile birlikte gösterilmektedir.

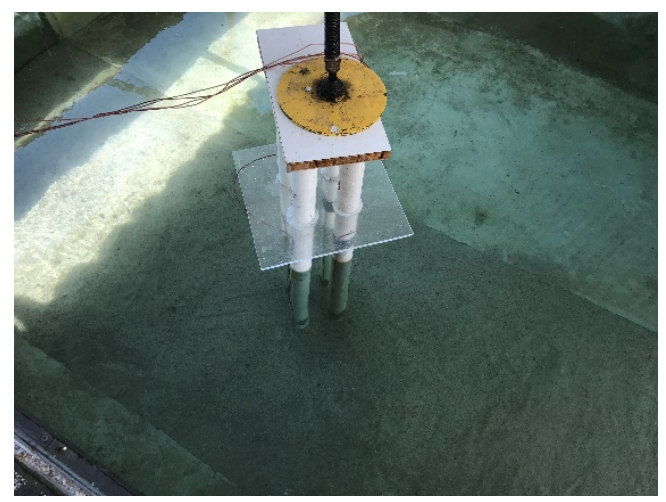

Şekil 8. Deneylerde dörtlü $45^{\circ}$ açı ile yerleştirilmiş kazık grubu ve oyulma ölçüleri için kullanılan UVP algılayıcıları. 
DEÜ FMD 22(66), 749-757, 2020

Tablo 1. Yan yana, arka arkaya ve dörtlü kazık grubu için gerçekleștirilen deneylerin özellikleri.

\begin{tabular}{|c|c|c|c|c|c|c|}
\hline Deney No & Kazık Gurubu & $\begin{array}{c}\mathrm{D} \\
(\mathrm{mm})\end{array}$ & $\begin{array}{c}\mathrm{d}_{50} \\
(\mathrm{~mm})\end{array}$ & $\begin{array}{c}\mathrm{H} \\
(\mathrm{cm})\end{array}$ & $\begin{array}{c}\mathrm{T} \\
(\mathrm{sn})\end{array}$ & $\begin{array}{c}\mathrm{L} \\
(\mathrm{cm})\end{array}$ \\
\hline 1 & $\mathrm{GA}^{*}$ & 110 & 0.55 & 6 & 5.4 & 1250 \\
\hline 2 & $\mathrm{GA}^{*}$ & 110 & 0.55 & 9 & 4.3 & 975 \\
\hline 3 & $\mathrm{GA}^{*}$ & 110 & 0.55 & 13 & 3.6 & 800 \\
\hline 4 & $\mathrm{GA}^{*}$ & 110 & 0.55 & 17 & 3.1 & 700 \\
\hline 5 & $\mathrm{GA}^{*}$ & 110 & 0.55 & 20 & 2.7 & 600 \\
\hline 6 & $\mathrm{GA}^{*}$ & 90 & 1.85 & 17 & 3.1 & 700 \\
\hline 7 & $\mathrm{GA}^{*}$ & 90 & 1.85 & 20 & 2.7 & 600 \\
\hline 8 & $\mathrm{GA}^{*}$ & 90 & 1.85 & 22 & 2.3 & 500 \\
\hline 9 & $\mathrm{GA}^{*}$ & 90 & 1.85 & 25 & 2.0 & 420 \\
\hline 10 & $\mathrm{GA}^{*}$ & 90 & 1.85 & 28 & 1.7 & 350 \\
\hline 11 & $\mathrm{GA}^{*}$ & 63 & 1.85 & 20 & 2.7 & 600 \\
\hline 12 & $\mathrm{GA}^{*}$ & 63 & 1.85 & 22 & 2.3 & 500 \\
\hline 13 & $\mathrm{GA}^{*}$ & 63 & 1.85 & 25 & 2.0 & 420 \\
\hline 14 & $\mathrm{GA}^{*}$ & 63 & 1.85 & 28 & 1.7 & 350 \\
\hline 15 & $\mathrm{GY}^{* *}$ & 110 & 1.85 & 22 & 2.3 & 500 \\
\hline 16 & $\mathrm{GY}^{* *}$ & 110 & 1.85 & 25 & 2.0 & 420 \\
\hline 17 & $\mathrm{GY}^{* *}$ & 110 & 1.85 & 28 & 1.7 & 350 \\
\hline 18 & $\mathrm{GY}^{* *}$ & 90 & 1.85 & 22 & 2.3 & 500 \\
\hline 19 & $\mathrm{GY}^{* *}$ & 90 & 1.85 & 25 & 2.0 & 420 \\
\hline 20 & $\mathrm{GY}^{* *}$ & 90 & 1.85 & 28 & 1.7 & 350 \\
\hline 21 & $\mathrm{GY}^{* *}$ & 63 & 1.85 & 22 & 2.3 & 500 \\
\hline 22 & $\mathrm{GY}^{* *}$ & 63 & 1.85 & 25 & 2.0 & 420 \\
\hline 23 & $\mathrm{GY}^{* *}$ & 63 & 1.85 & 28 & 1.7 & 350 \\
\hline 24 & $\mathrm{GD} 45^{* * *}$ & 63 & 0.55 & 6 & 5.4 & 1250 \\
\hline 25 & GD $45^{* * *}$ & 63 & 0.55 & 13 & 3.6 & 800 \\
\hline 26 & $\mathrm{GD} 45^{* * *}$ & 63 & 0.55 & 17 & 3.1 & 700 \\
\hline 27 & $\mathrm{GD} 45^{* * *}$ & 63 & 0.55 & 20 & 2.7 & 600 \\
\hline 28 & GD90**** & 63 & 0.55 & 6 & 5.4 & 1250 \\
\hline 29 & GD90**** & 63 & 0.55 & 9 & 4.3 & 975 \\
\hline 30 & GD90**** & 63 & 0.55 & 13 & 3.6 & 800 \\
\hline 31 & GD90**** & 63 & 0.55 & 17 & 3.1 & 700 \\
\hline 32 & GD90**** & 63 & 0.55 & 20 & 2.7 & 600 \\
\hline 33 & GD90**** & 63 & 1.85 & 22 & 2.3 & 500 \\
\hline 34 & GD90**** & 63 & 1.85 & 25 & 2.0 & 420 \\
\hline 35 & GD90**** & 63 & 1.85 & 28 & 1.7 & 350 \\
\hline 36 & GD $45^{* * *}$ & 63 & 1.85 & 22 & 2.3 & 500 \\
\hline 37 & GD $45^{* * *}$ & 63 & 1.85 & 25 & 2.0 & 420 \\
\hline 38 & GD $45^{* * *}$ & 63 & 1.85 & 28 & 1.7 & 350 \\
\hline
\end{tabular}

* Aynı çaplı iki kazığın arka arkaya yerleștirilmesi ile olușan kazık grubu

** Aynı çaplı iki kazığın yan yana yerleştirilmesi ile oluşan kazık grubu

*** Aynı çaplı dört kazığın dalga geliş yüne göre $45^{\circ}$ açı ile yerleștirilmesi ile oluşan kazık grubu

**** Aynı çaplı dört kazığın dalga geliş yüne göre $90^{\circ}$ açı ile yerleştirilmesi ile oluşan kazık grubu

Şekil 9 ile Şekil 12 arasında sırasıyla dalga ilerleme yönüne göre birbiri ardına yerleștirilen ikili kazık durumu, dalga ilerleme yönüne göre yan yana yerleştirilen ikili kazık durumu, dalga ilerleme yönüne göre $90^{\circ}$ açı ile yerleştirilen dörtlü kazık grubu ve dalga ilerleme yönüne göre $45^{\circ}$ açı ile yerleștirilen dörtlü kazık grubu için elde edilen taban batimetrisi verilerine örnekler sunulmaktadır.

Şekil 11 ve 12 incelendiğinde, nihai taban batimetrisindeki nispeten asimetrik oyulma/yı̆̆ılma yapısının, aralarında bir çap 
boşluk olan dörtlü kazık grubunun tekil bir geniş kazık gibi davranış göstermesinden kaynaklandığı düşünülmektedir.

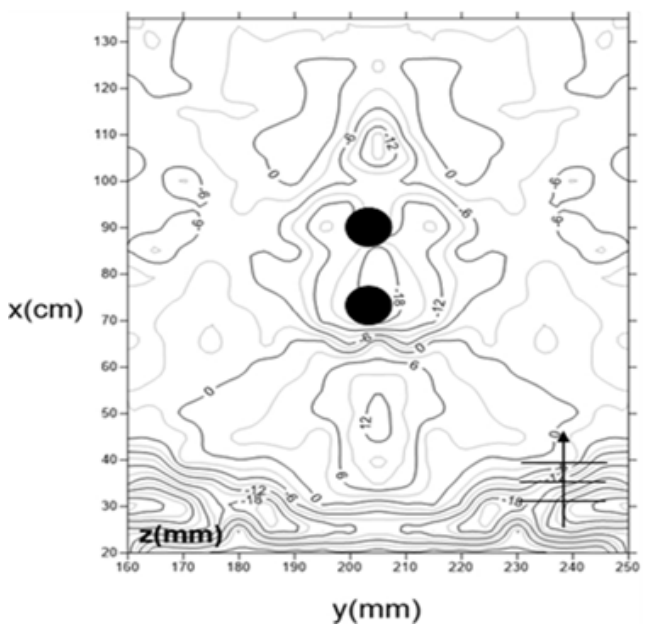

Şekil 9. 9 nolu deney sonrasında elde edilen taban batimetrisi.

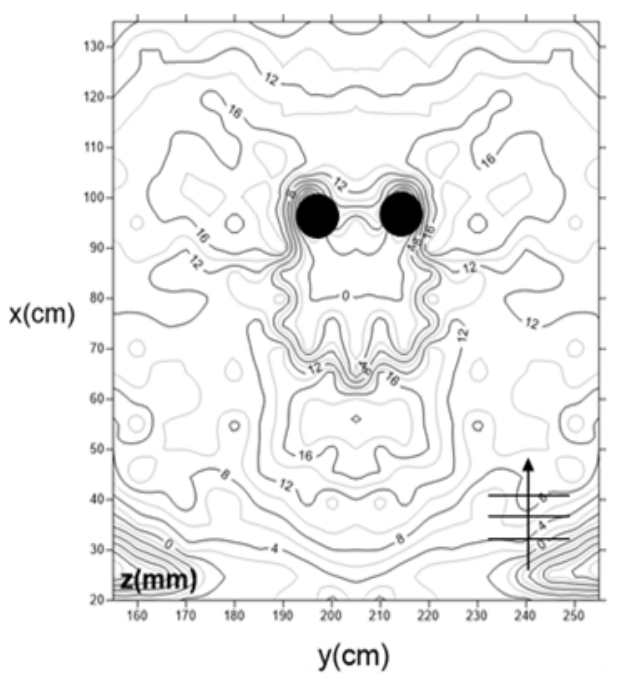

Şekil 10. 20 nolu deney sonrasında elde edilen taban batimetrisi.

Şekil 13 ve 14'te Tablo 1'de bilgileri verilen 14 nolu deney kapsamında birbiri ardına yerleştirilen aynı çaplı iki kazığa bağlı olan UVP algılayıcılarındaki zamana bağlı oyulma derinlikleri ham verileri gösterilmektedir.

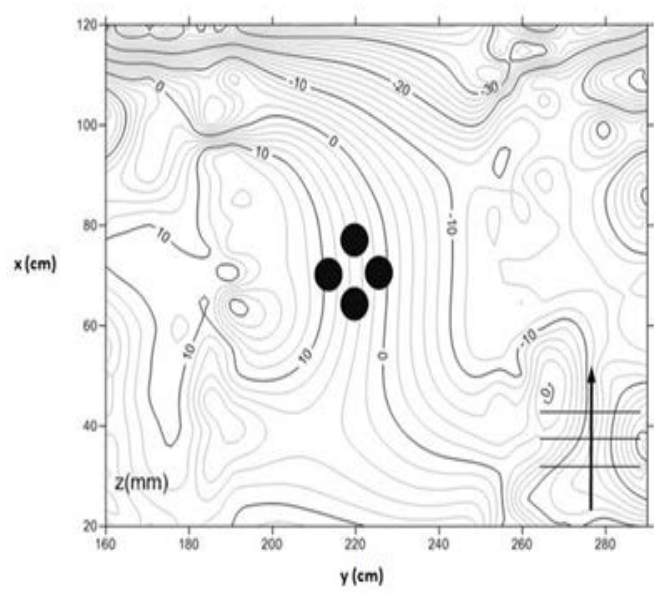

Şekil 11. 26 nolu deney sonrasında elde edilen taban batimetrisi.

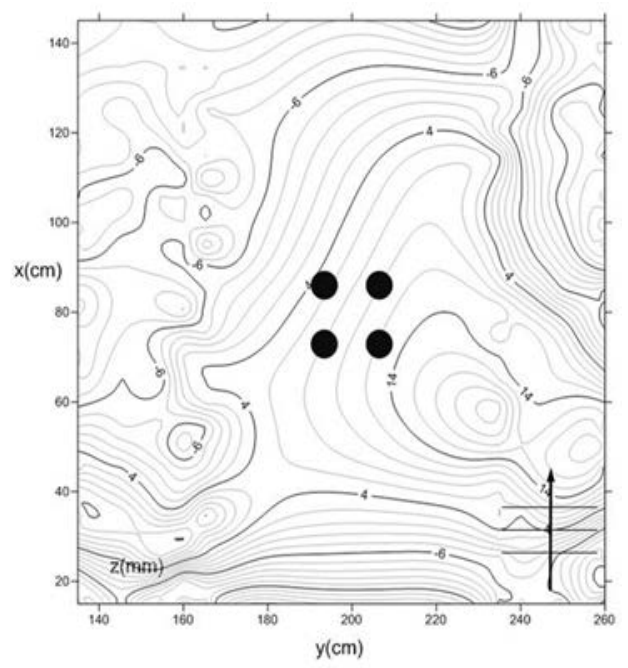

Şekil 12. 29 nolu deney sonrasinda elde edilen taban batimetrisi.

Şekil 15 ve 16'da Tablo 1'de bilgileri verilen 17 nolu deney kapsamında yan yana yerleștirilen aynı çaplı iki kazığa bağlı olan UVP algılayıcılarındaki zamana bağlı oyulma derinlikleri ham verileri gösterilmektedir.

Șekil 17, 18, 19 ve 20'de Tablo 1'de bilgileri verilen 26 nolu deney kapsaminda dalga ilerleme yönüne göre $45^{\circ}$ açı ile yerleștirilen dörtlü kazığın her birinin etrafındaki UVP algılayıcılarında ölçülen zamana bağlı oyulma derinlikleri ham verileri gösterilmektedir. 
DEÜ FMD 22(66), 749-757, 2020

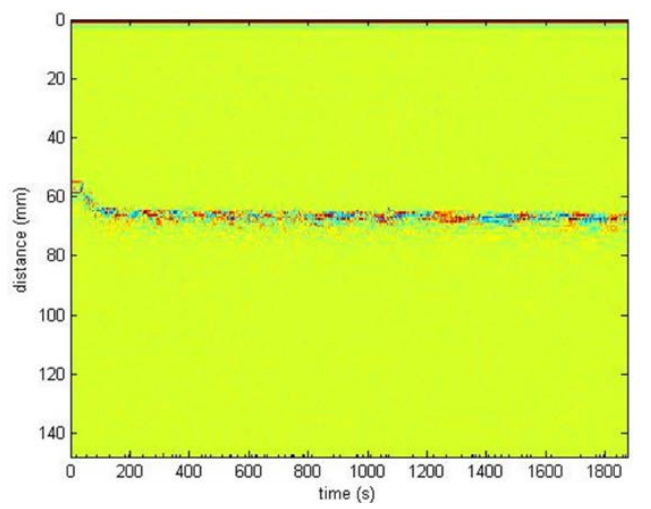

Şekil 13. 14 nolu deneyde dalga ilerleme yönüne göre öndeki kazık etrafında oluşan oyulmanın zamana bağlı değişimi.

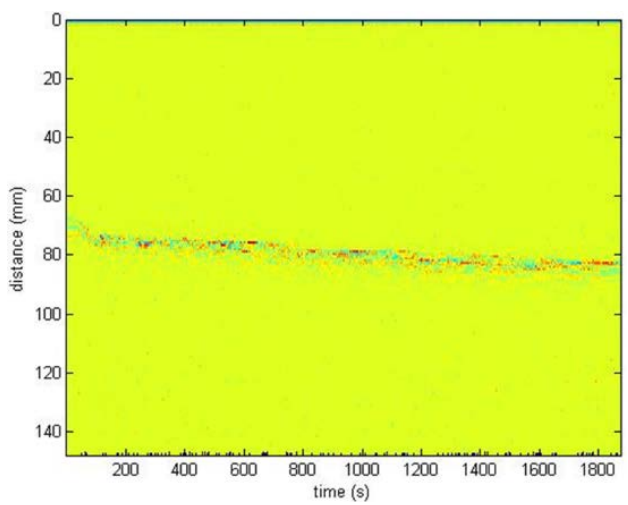

Şekil 14. 14 nolu deneyde dalga ilerleme yönüne göre arkadaki kazık etrafında oluşan oyulmanın zamana bağlı değişimi.

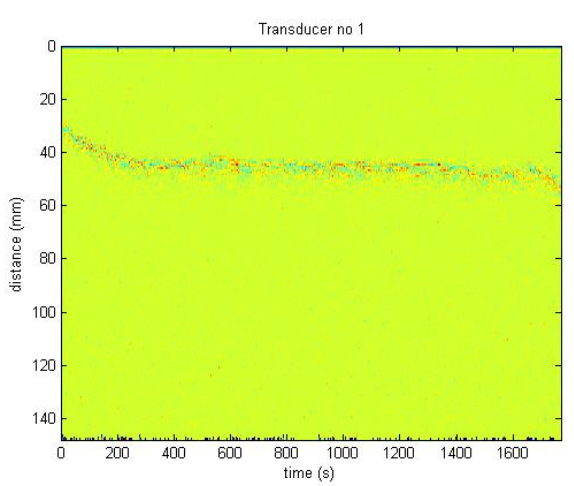

Şekil 15. 17 nolu deneyde dalga ilerleme yönüne göre sağdaki kazık etrafında oluşan oyulmanın zamana bağlı değişimi.

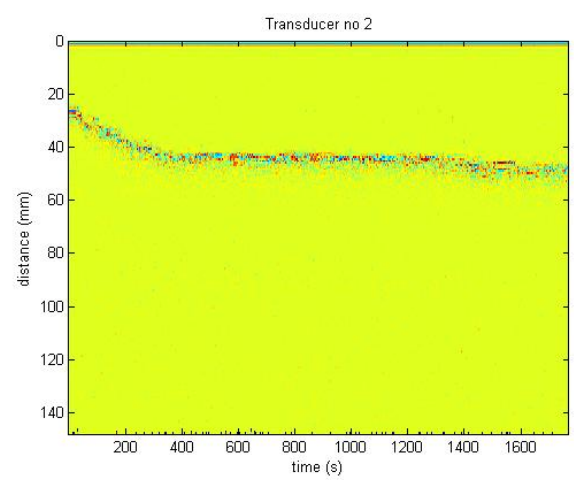

Şekil 16. 17 nolu deneyde dalga ilerleme yönüne göre soldaki kazık etrafında oluşan oyulmanın zamana bağlı değişimi.

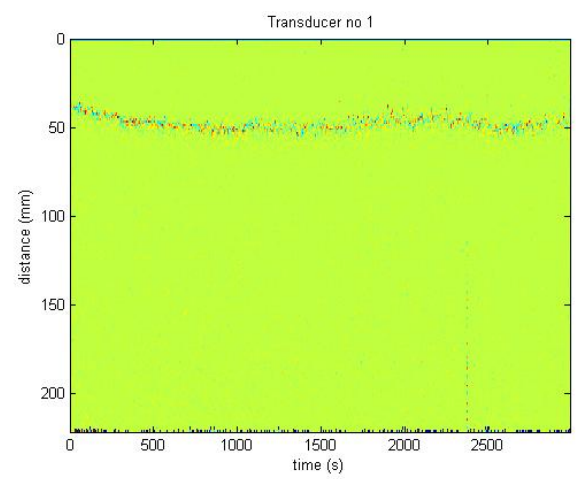

Şekil 17. 26 nolu deneyde dalga ilerleme yönüne göre en öndeki kazık etrafında oluşan oyulmanın zamana bağlı değișimi.

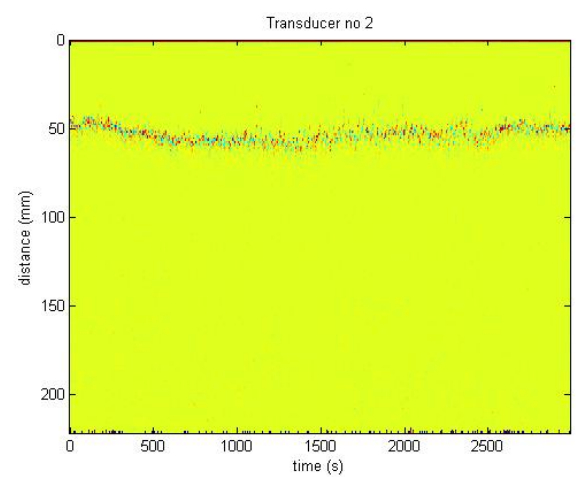

Şekil 18. 26 nolu deneyde dalga ilerleme yönüne göre sağdaki kazık etrafinda oluşan oyulmanın zamana bağlı değişimi. 


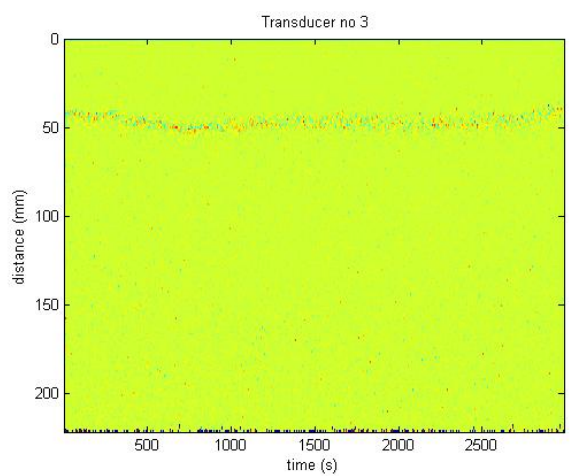

Şekil 19. 26 nolu deneyde dalga ilerleme yönüne göre soldaki kazık etrafında oluşan oyulmanın zamana bağlı değişimi.

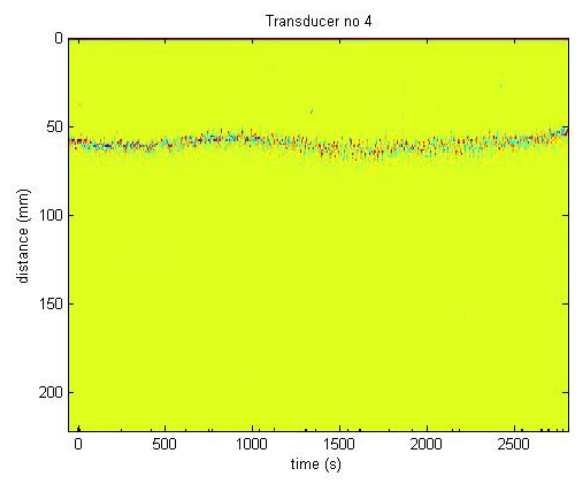

Şekil 20. 26 nolu deneyde dalga ilerleme yönüne göre en arkadaki kazık etrafında oluşan oyulmanın zamana bağlı değişimi.

Şekil 21, 22, 23 ve 24'te Tablo 1'de bilgileri verilen 32 nolu deney kapsamında dalga ilerleme yönüne göre $90^{\circ}$ açı ile yerleştirilen dörtlü kazığın her birinin etrafindaki UVP algılayıcılarında ölçülen zamana bağlı oyulma derinlikleri ham verileri gösterilmektedir.

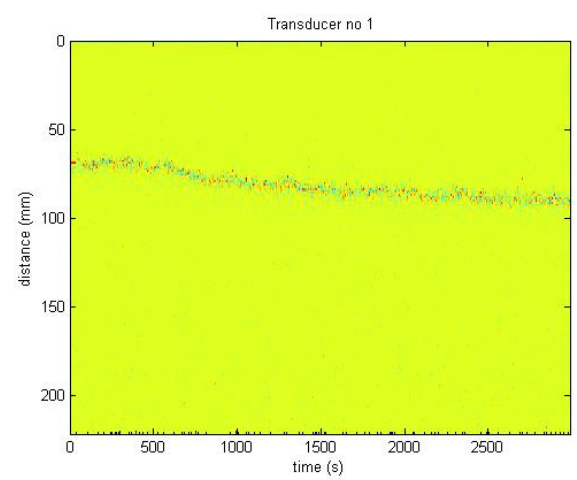

Şekil 21. 32 nolu deneyde dalga ilerleme yönüne göre sağ öndeki kazık etrafında oluşan oyulmanın zamana bağlı değişimi.

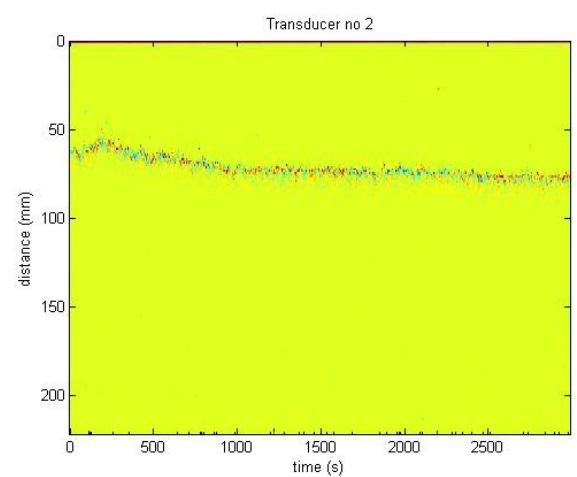

Şekil 22. 32 nolu deneyde dalga ilerleme yönüne göre sol öndeki kazık etrafında oluşan oyulmanın zamana bağlı değişimi.

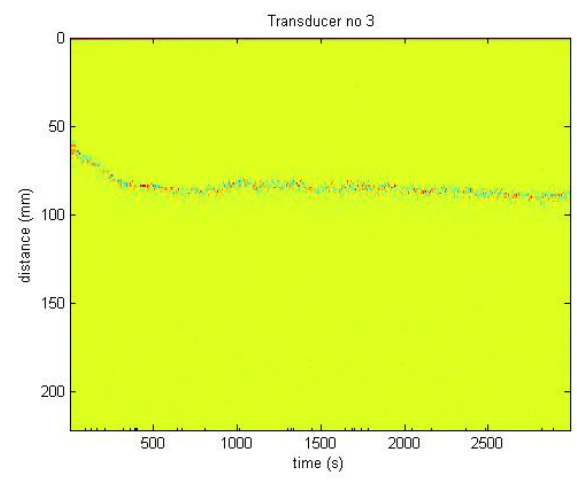

Şekil 23. 32 nolu deneyde dalga ilerleme yönüne göre sağ arkadaki kazık etrafında oluşan oyulmanın zamana bağlı değişimi. 


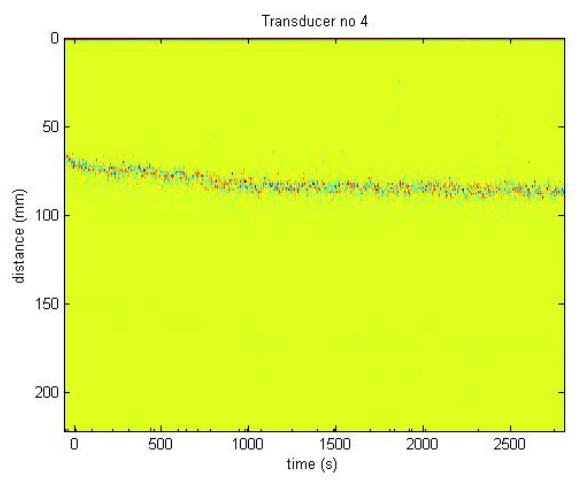

Şekil 24. 32 nolu deneyde dalga ilerleme yönüne göre sol arkadaki kazık etrafında oluşan oyulmanın zamana bağlı değişimi.

\section{SONUÇ VE ÖNERILLER}

Gerçekleştirilen deneysel çalışma kapsamında denen tüm kazık grupları, tekil kazıklar arasında bir çap kadar boșluk olacak șekilde yerleștirilmiştir.

Calıșma sonucu temel olarak elde edilen en önemli bulgu; kazık grupları etrafında nihai durum için çıkarılan taban batimetrisi sonuçlarından yararlanılarak bulunan genel oyulma değerinin, kazıkların her birinin etrafında zamana bağlı ölçülen oyulma derinliklerinden elde edilen yerel oyulma değerlerine göre büyük olduğudur. $\mathrm{Bu}$ durum özellikle dalga ilerleme yönüne göre $45^{\circ}$ ve $90^{\circ}$ yerleşimli dörtlü kazık grubu ile gerçekleştirilen deneysel çalıșmalarda daha belirgin bir șekilde karşımıza çıkmaktadır. Dörtlü kazık durumunda, her iki yönde aralarında bir çap boşluk bulunan dörtlü kazıkların büyük çaplı büyük bir kazık gibi davrandığı ve böylece tekil kazık durumundakinden daha büyük oyulmaların kazık grubu etrafında oluștuğu anlaşılmaktadır.

Yine dörtlü kazık gruplarında dalga ilerleme yönüne göre arkada kalan kazıkların etrafında oluşan oyulmaların öndeki kazıkların etrafındaki oyulmadan büyük kaldığı anlașılmaktadır. Bu durum aynı çaplı iki kazığın dalga ilerleme yönüne göre arka arkaya yerleştirilmesi ile oluşturulan iki kazık grubu deneylerinde de görülmektedir.

Deneysel çalışmalar kapsamında kullanılan taban malzemelerinin çapları birbirlerinden önemli ölçüde farklı olduğundan, taban malzemesinin oyulma sürecine etkisi de yorumlanabilmiștir. Deneysel bulgular beklendiği gibi iri taban malzemesi durumunda ölçülen oyulmaların aynı șartlardaki ince daneli taban malzemesi ile gerçekleştirilen deneylerdeki oyulmadan küçük kaldığını göstermektedir.

Kazık grupları ile gerçekleştirilen deneylerde, zamana bağlı ölçümler ve nihai taban batimetrileri incelendiğinde, aralarında bir çap mesafe bulunan kazık gruplarının neredeyse iki tekil kazık gibi davrandığı ancak bu değerin yarım çapa düşmesi durumunda kazık grup etkisinin ortaya çıktığı anlaşılmıștır. Ayrıca, dörtlü kazık grubu durumunda kazıklar etrafındaki yerel oyulmalara ek olarak dörtlü grup etrafında genel bir oyulma durumu da söz konusudur.

Birey kazık için belirlenen oyulma derinlikleri, grup kazık durumunda genel oyulma yapısı olarak daha büyük değerlerde karşımıza çıkmaktadır. Bu durumda kazıklı kıyı yapılarının tekil kazık durumuna göre projelendirilmelerinin yanı sıra kazık grup etkisinin de tahkik edilmesi, stabilite açısından büyük önem taşımaktadır.

\section{Teşekkür}

$\mathrm{Bu}$ çalışmayı 215M245 numaralı araştırma projesi ile destekleyen Türkiye Bilimsel ve Teknolojik Araștirma Kurumu'na (TÜBİTAK) teșekkür ederiz.

\section{Kaynakça}

[1] Sumer B.M., Fredsøe J.1998. Wave scour around group of vertical piles. ASCE J Waterway, Port Coastal Ocean Eng. 1998; 124(5):248-255.

[2] Mostafa, Y.E., Agamy, A.F. 2011. "Scour Around Single Pile and Pile Groups Subjected To Waves and Currents" International Journal of Engineering Science and Technology, 3 (11), 8160-8178.

[3] Najafzade.M.,Azamathulla.H.A. 2014. Neuro-Fuzzy GMDH to Predict the Scour Pile Groups due to Waves: American Society of Civil Engineers. DOI: 10.1061/(ASCE)CP.1943-5487.0000376.

[4] Guney, M. S., Bombar, G., Ozgenc Aksoy, A. ve Dogan, M. 2013. "Use of UVP to investigate the evolution of bed configuration." KSCE Journal of Civil Engineering, 17 (5), 1188-1197. 